\title{
U(rano)topia: spectral skies and rainbow holograms for silica aerogel artworks
}

\author{
loannis Michaloudis $\mathbb{D}^{1} \cdot$ Kazuyoshi Kanamori $\mathbb{D}^{2} \cdot$ Ifigenia Pappa ${ }^{3} \cdot$ Nikolaos Kehagias $\mathbb{D}^{4}$
}

Received: 17 July 2021 / Accepted: 25 October 2021

(c) The Author(s), under exclusive licence to Springer Science+Business Media, LLC, part of Springer Nature 2022

\begin{abstract}
Micro/nano structuring in distinct chemical compositions has demonstrated added values which could be utilized in various modern applications and products through the lens of visual arts. Silica aerogel is a prominent example of such a nanostructure, with which we recently utilized to accommodate the unique design of high jewelry. Using its natural shades and transparent layers, silica aerogel can be described by the first author, a visual artist, as an extremely beautiful and ethereal material that closely resembles a piece of sky. Ultimately silica aerogel can be exploited as a skylike material, and has been used in numerous collaborations amongst artists and scientists to bring to life concepts, like rainbow holograms on silica aerogel dried by high-temperature supercritical drying with methanol. In this short review, we show how such collaborations the authors have been proceeding are evoking developments in science and technology as well as in design, fashion and art industries. The series of the collaborative research has been contributing to the development of quality end products by merging new technologies, novel functional materials and innovative manufacturing processes with visual arts.
\end{abstract}

\section{Graphical Abstract}

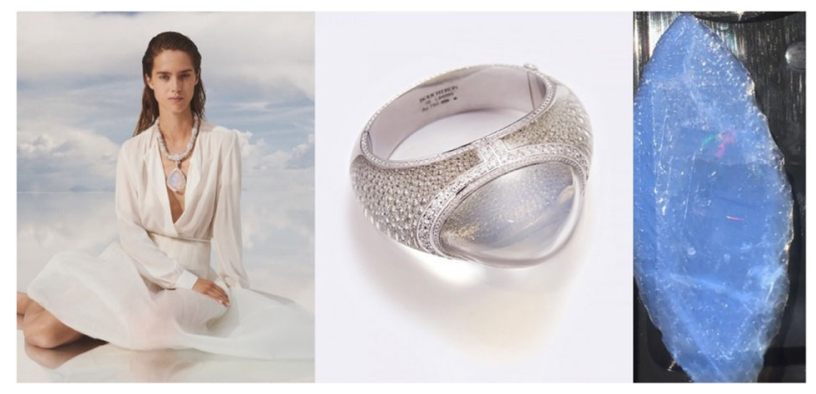

Keywords Aerogel $\cdot$ Visual arts $\cdot$ High jewelry $\cdot$ Rainbow hologram $\cdot$ Nanopatterning $\cdot$ Roll-to-roll nanoimprint lithography

Supplementary information The online version contains

supplementary material available at https://doi.org/10.1007/s10971-

021-05676-x.

Ioannis Michaloudis

ioannis.michaloudis@aucy.ac.cy

1 Faculty of Arts \& Humanities, American University of Cyprus (AUCY), Larnaca, Cyprus

2 Department of Chemistry, Graduate School of Science, Kyoto University, Kyoto, Japan
3 Department of Product and Systems Design Engineering, University of Aegean, Syros, Greece

4 Institute of Nanoscience and Nanotechnology, NCSR Demokritos, Athens, Greece 


\section{Highlights}

- Unique spectral property of silica aerogels evoked the creation of sky in visual arts.

- High jewelries composed of a celestial silica aerogel have been developed.

- Roll-to-Roll nanoimprint lithography has been applied to incorporate rainbow on a silica aerogel.

\section{Introduction to ambiguity}

In the general title of this paper, we have the presence of a duo of parentheses. The image of a parenthesis in the word U(rano)topia can only announce an ambiguity... On ambiguity, the poet Octavio Paz marked: "Modernity is consciousness. And ambiguous consciousness: negation and nostalgia, prose and lyricism [1]".

$\boldsymbol{U}($ rano)topia is an invented word composed by Uranos, the "sky" in Greek and utopia. The bold characters and the use of parenthesis improve this arrangement, as we want to support the idea that our uranotopic works can become ambiguous immaterial «sky souvenirs» forming our terrestrial cultural memory... Those same sky souvenirs from an earthborn sky, our clones will carry with them while colonizing space...

The research project $\boldsymbol{U}$ (rano)topia is the continuation of our aer()sculpture project, an innovative worldwide pioneering Art \& Science project, aiming the creation of weightless, ethereal sculptures using sculptural medium of the silica aerogel as a space nanomaterial. This "unobtainium" material, is the lightest solid material on earth. Aesthetically it is called solid smoke and extremely light due to the fact that it comprises in such a unique manner that up to $99.8 \%$ of its volume is ultimately pure void surrounded by a jungle of glass!

This ambiguity between thesis and antithesis becomes evident thanks to the single pair of parentheses ...

\section{Silica aerogel for art: spectroscopic aspects}

The origin of the ambiguity should be explained from a scientific viewpoint to connect the philosophy to the material. Silica aerogel makes itself a unique material by its high visible-light transparency and high porosity. Typically prepared through the water-glass process and sol-gel process from alkoxysilane precursors such as tetramethoxysilane (TMOS) and tetraethoxysilane, silica colloids are developed by the hydrolysis and polycondensation, and they form thin solid skeletons by linking together three dimensionally. The resultant microstructure and appearance of a typical silica aerogel is shown in Fig. 1 [2]. Thin skeletons of $\sim 10 \mathrm{~nm}$ form the mesoporous framework in the size range of $\sim 50 \mathrm{~nm}$, which minimizes the Mie scattering and allows transparent appearance [3]. Tailoring a fine, homogeneous skeletal/porous structure via one-step strong base or two-step acid-base process is known to lead to highly transparent silica aerogels with low enough haze $[4,5]$. Meanwhile, due to the Rayleigh scattering by the colloidal network, silica aerogel looks bluish, for the similar reason to the blue sky.

Ultraviolet-visible (UV-Vis) transmission spectra shown in Fig. 2 explain the scattering behavior in silica aerogel. The diffusional transmission in part (b) shows the characteristic scattering; i.e., the shorter wavelength components in the visible light are more strongly scattered as the Rayleigh scattering is proportional to $\lambda^{-4}$. Oppositely, it can be

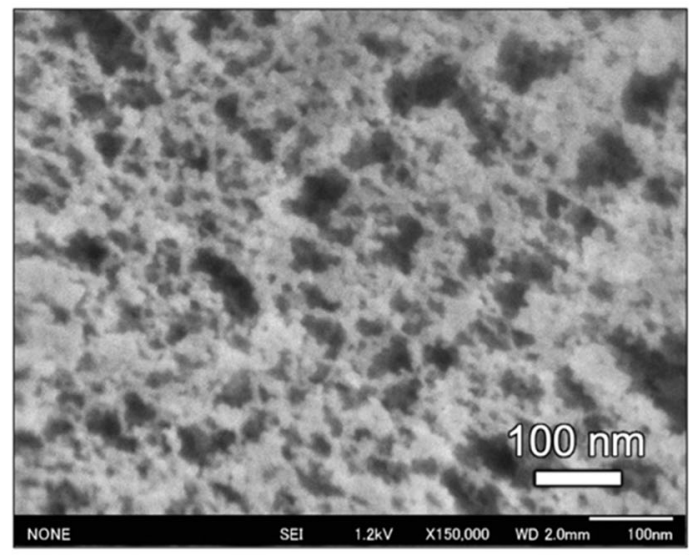

Fig. 1 Scanning electron micrograph (left) and appearance (right) of a typical aerogel (SP-15, Matsushita Electronic Works (present Panasonic), Japan). The Rayleigh scattering occurs predominantly by the

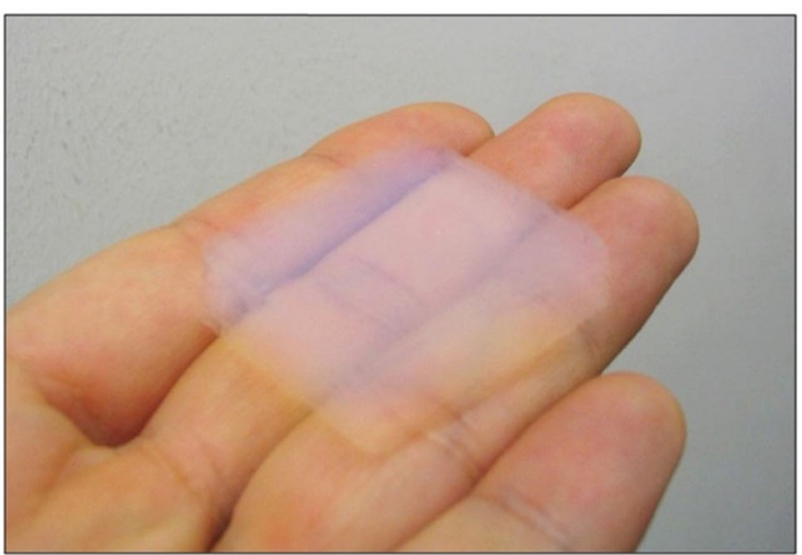

colloidal particles of $\sim 10 \mathrm{~nm}$, which constitutes the solid skeleton and porous structure 


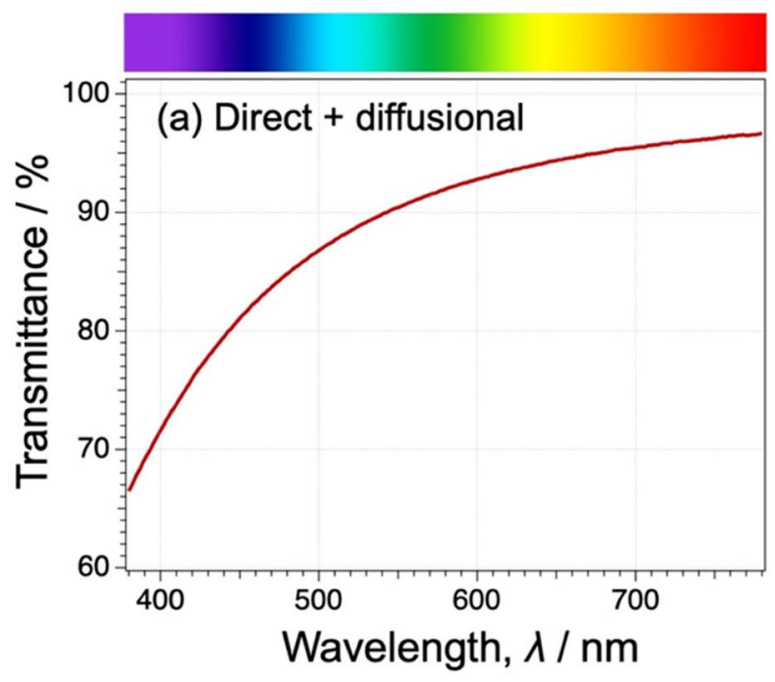

Fig. 2 a Total light transmittance spectrum and b diffusional light transmittance spectrum of the same material shown in Fig. 1 (thickness $\sim 10 \mathrm{~mm}$ ) in the visible region (380-780 nm), measured using a UV-Vis spectrometer equipped with an integrated sphere. The "sky blue" appearance of aerogels predominantly come from the Rayleigh

confirmed in part (a) that the longer wavelength components can transmit through the aerogel more efficiently. This behavior makes the transmitted light orangish, for the similar reason to the sunset.

Another attractive aspect of silica aerogel is low refractive index. The high porosity, equivalent to low solid concentration in an aerogel body, drastically reduces interactions of light and aerogel, which leads to the low refractive index. The relationship between refractive index $\mathrm{n}$ and aerogel density $\rho / \mathrm{g} \mathrm{cm}^{-3}$ is known to follow the empirical equation [6]

$n=1+0.21 \rho$

by which the typical silica aerogel $\left(0.20 \mathrm{~g} \mathrm{~cm}^{-3}\right)$ subjected to the hologram design described later is found to have refractive index around 1.04, which is well lower than that of water ( 1.33) and closer to that of air ( 1.00).

Since the refraction (and also reflection) of light is highly suppressed at the interface between an aerogel and surrounding atmosphere, giving itself the smoky, ambiguous impression. All the aesthetic presentations described here, from a viewpoint of silica aerogel as the space technology as described later, are derived from these unique properties.

\section{Space technology applied in art and design}

Over the past 20 years, one of the authors, IM, has experimented with silica aerogel as a sculptural medium. Originally designed as a space technology nanomaterial

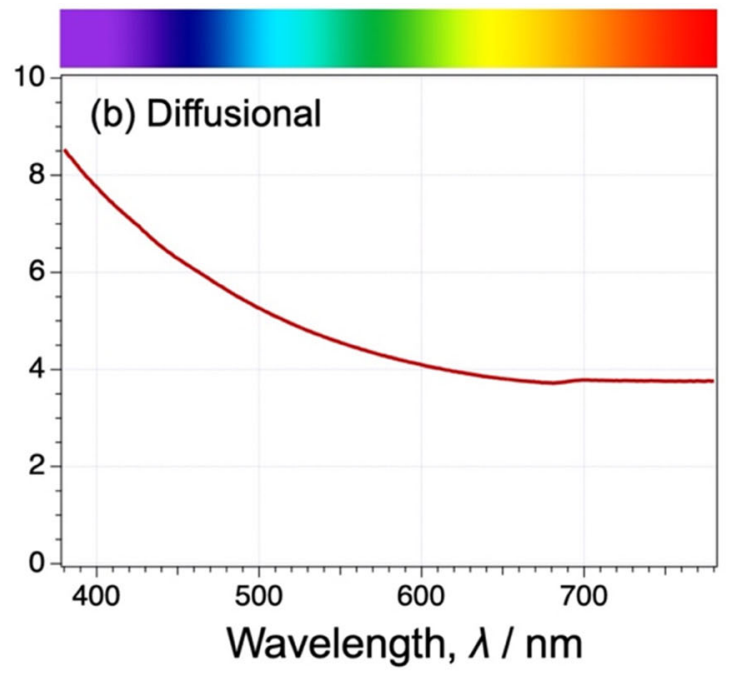

scattering, intensity of which is proportional to $\lambda^{-4}$ and the light of shorter wavelength is more intensely scattered. Oppositely, the transmitted white light loses the shorter wavelength component, so its color looks orangish

to capture stardust and act as an insulator, IM has for the first time transferred this nanomaterial to artistic projects, concerning notions and allegories associated with the creation of sky, clouds and ether (examples are shown in Fig. 3).

The novelist Marcel Proust states that "the creation can only take place on condition whereas the superficial ego is put in a parenthesis, that it is effaced to make room for another ego, disinterested, an original ego to which the imperatives of social life impose silence, but which in fact represents the inner necessity to which the work obeys [7]". If the artist must therefore "die" as a human being in order to be reborn as another entity, then if the Self pushes the Me and the $I$ to annihilation, in this case how can another person be found and defined, which will have the capacity to take upon the responsibility of transforming the same artistic products/actions but this time translated in some kind of writing format?

With the same aim of "transfiguration", the painter Marcel Duchamp used the term writer [8] in 1934. The term "writer" is quite accurate in describing the actions of the individual performs, but it does not have the gravity to replace the creative process of a visual artist. In modern Greek there is a word which could perfectly take the place of the words I, writer, or author. It is the word glossoplastes which means "plastician of tongue-language". However, it is another compound word, which will replace the $I$ of IM as the plastician: the term "plastograph". In modern Greek plastographos (from plastos "false" and graphein "to write") is the "counterfeiter", the "falsifier". 
(a)

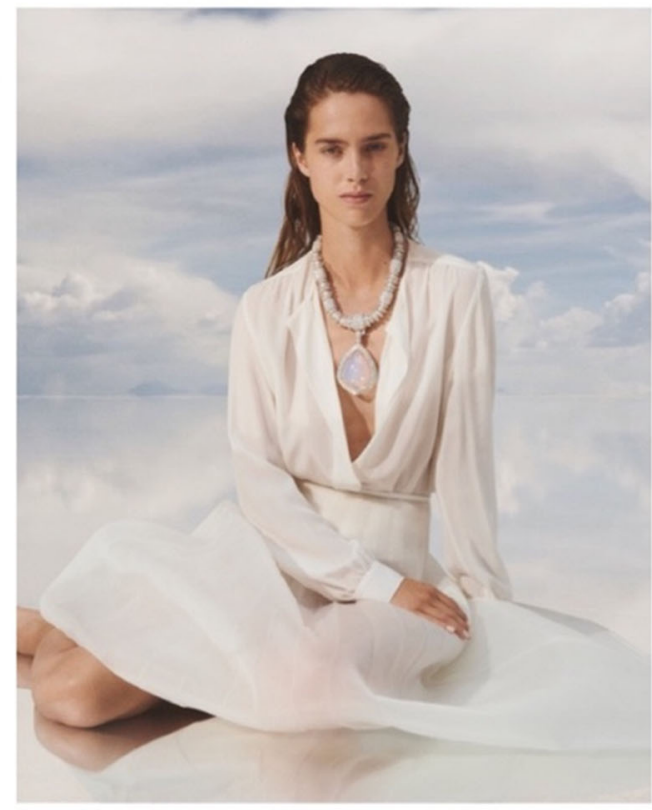

(b)

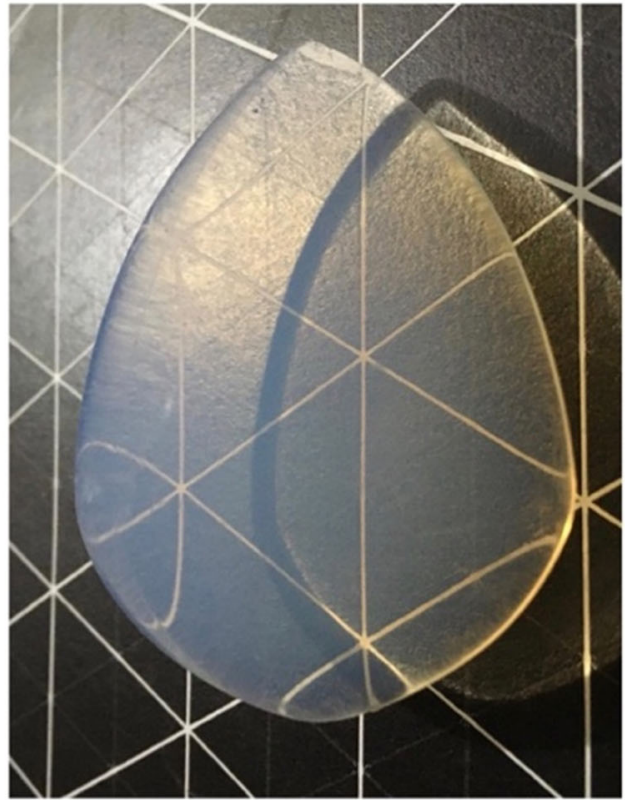

(c)

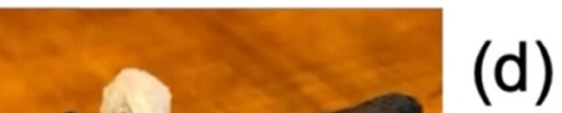

Fig. 3 Staring in 2018 and for 2 years, IM collaborated with Claire Choisne, the creative director of the jewelry company Boucheron for the creation of the first-ever silica aerogel high jewelry "Goutte de ciel", Skydrop (a-c). A movie for this figure is also available in the

This fragmented, prosaic and "paragraphic" appearance of this paper is an allegory of the fragmented, shattered nature of our sky of today.

The word "paragraph" (from the Greek paragraphos "written beside"), is the division of a writing into prose, offering a certain unity of thought or composition. The paragraph is also the typographic sign $\S$, showing the number of a subsection.

From the "falsifier" and the symbol of the paragraph (resembling two $\mathrm{S}$ or two coupled snakes) therefore derives
Supplementary Material (Mov. S1). d A bracelet composed with silica aerogel collaborated with the same company. Courtesy of Boucheron, Paris, July 2020

the term "plastograph" which is replacing the "I" of the plasticien when he is paragraphing here...

This (paren)thesis does not ask to be read but seen. For the plastograph, writing is a primarily visual tool that firstly shows words to be seen... Any word, before being read, known and recognized, first it is seen. In his words, the plastograph aims to the signifier, to the "seen" of the word; better still: the plastograph targets the "seen it otherwise" of the words.

Each of IM's artworks has a blue and orange natural colors for the same reason the sky is blue: the Rayleigh 
scattering phenomenon, as mentioned earlier. Aerogels contain nanopores filled with air that are only a few hundred times larger than atoms. The skeletons constructing these nanopores are made of silica gel, which is what glass is made of, and the interface between the solid and air scatters visible light to make the aerogel appear blue and orange. Thus, keeping a piece of silica aerogel in your hand is like you have a piece of (sculpted) sky in between your fingers!

"I put up my thumb and shut one eye, and my thumb blotted out the planet earth. I didn't feel like a giant, I felt very, very small'. In his account of his trip on Apollo 11, Neil Armstrong laconically details the profound effect such a momentous shift in perspective.

\section{Aerogelic scale}

Silica aerogel is a material of extremely small inner dimensions and has a transparent body; thus, it can be used in visual arts as a kind of diaphanous body, a transparent slide for projections. This mask of light is like a device where its "microchoros" contains in systole all the "macrochoros" of the forest. "From one forest to another, from the forest in diastole to the forest in systole, a cosmicity breathes [9]"...

In the last few decades, the understanding of interfacial phenomena and the use of novel smart materials, particularly at a micro- and nano-meter scale, has played a fundamental role in the development of many scientific and technological fields. Their integration in structures or in devices could introduce new functionalities, enhance energy efficiency, etc. in working systems applicable to multiple industrial sectors.

In philosophy, a Platonic dialectic approach regarding dimensions, large or small will not be adequate to describe and capture the dynamic virtues of a miniature. Values rush into the miniature that makes us dream. The miniature is one of the lodges of greatness [10].

"The proportions and the scales are not found outside the artist, but in him. They are what we can also call the sense of limits, the artistic tact-innate qualities of the artist which can, by enthusiasm, be exalted to the point of brilliant revelation [11]". A scale is the "child mastered" on a seesaw. The only thing that masters a seesaw is the game... The scale transforms this game into a mastery, a measure...

Silica aerogel is indeed a remarkable material; some $99 \%$ air and $1 \%$ glass. A particular silica aerogel made at NASA's Jet Propulsion Laboratory approaches the density of air $(3 \mathrm{~kg} /$ $\mathrm{m}^{3}$ vs. $1.3 \mathrm{~kg} / \mathrm{m}^{3}$ ) [12]. Aerogel is unique not only for how it is and what it is. Aerogel is remarkable also for its strangeness, its aesthetic queerness; what it evokes in the beholder; how it appears. To hold a 'lump' of silica aerogel in one's hand is an unnerving experience. Immediately, its conspicuous un-lumpiness is exposed. A material unlike anything else one might have held before [13].

The lightness of silica aerogel is ethereal, and a property that IM wields to his advantage, incorporating it in strange and in between spaces.

The material—silica aerogel or logos-is directly related to time and space. It has a body; and this body is challenged daily with these two adversaries. Time and space are there to enable the material to exist in a state of resistance. This writing will therefore examine the nanomaterial-more precisely the transformation, the metamorphosis of the silica aerogel nanomaterial once it becomes a habitat of the sunlight (Fig. 4).

Habit or habitat are primarily materials becoming materialities fulfilled with time and space. They will be formed and transformed by them-through human intervention. Through several trans/formations, the latter thus succeeded in "using" the first nature of the material, in order to transform it in materiality: the cry in logos.

\section{Plasticity versus elasticity: the Skotography}

Plasticity in science is a property for a material that does not recover its shape when a deformation occurred. Elasticity is for that does recover. For IM, plasticity is the knowledge of a material moving towards... Elasticity is the memory of a material, its return from... If plasticity equals gnosis, then elasticity will be analogous to mneme, memory [14]

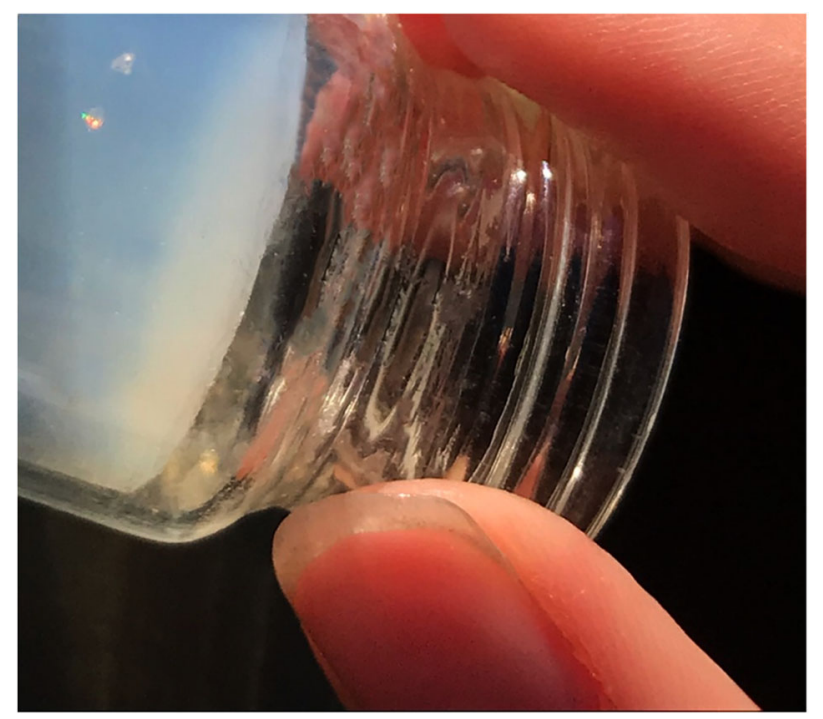

Fig. 4 During his collaboration with the jewelry company Boucheron, the first author had tested successfully to incorporate $0.05 \mathrm{Ct}$ round diamonds into the silica aerogel. Here, direct sunlight is bent into the prismatic structure of the diamond gemstone and the rainbow spectrum appears inside the solid artificial sky of silica aerogel. A movie for this figure is also available in the Supplementary Material (Mov. S2). Photo and (C) MICHALOUS, 2019 
It is only thanks to the memory that we manage to "burn" our past, to master it, to prevent it from intervening in the present: memory plays the capital role. We get rid of the work of time by reminiscence, anamnesis. The one who is able to remember himself has a magico-religious force even more precious than the one who knows the origin of things [15].

The conceptual artist Joseph Beuys was concerned for plasticity as much in his works as in language, but also, he was keen on observing for the temperature which can transform-by melting - this plasticity. Moreover, to identify the roots of Beuys' formula "language = plasticity", we should go back to Plato, who, in the ninth book of the Republic, defines logos and speech as materials of plasticity.

Accepting the color as a symbol, seems to be a question of both memory and necessity.

The chros, the color is not the last surface of a material, the last one is the light. It is this which becomes the chros, the epidermis, the interface for any exchange... Thanks to the color, a surface can be seen. However, the light can also become the Materia prima of this surface: the same light can penetrate deeply into a Naxian marble, just as it can only glide over the epidermis of a lump of coal [16].

Each excavating of the light risks discovering another epidermis: the one on the other side...

"The eye is more or less strongly attracted by light colors, and even more strongly by lighter, warmer colors: vermilion red attracts and irritates the eye like the flame that man contemplates irresistibly" [17].

Photography is only reduced to a proper photo-graphia, a "writing of light" and not to a "chromatography" (from chroma- "color").

Perseus becomes a civilizing hero thanks to light, phos, and the cunning of the mirror. He makes Medusa passive because he is active. He presents himself as a warrior before a woman-mother.

In Greek mythology Skotos is the complete opposite of Phos, he is that "Dark Night" before creation. Skotos, "darkness", is therefore underground, even "sub-cosmic" since it existed even before Earth. In modern Greek, skotos continues to refer to "darkness". Photography or skotography? An example of photography on silica aerogel has been demonstrated using a $\mathrm{CO}_{2}$ laser [18].

\section{6 (C)over a rainbow}

A hypothesis of IM-years now-is that if a piece of the nanomaterial silica aerogel looks like a sky fragment [19], can we imagine other sky phenomena like halos or rainbows (Fig. 5) to appear into this artificial fragment of sky [20]? In

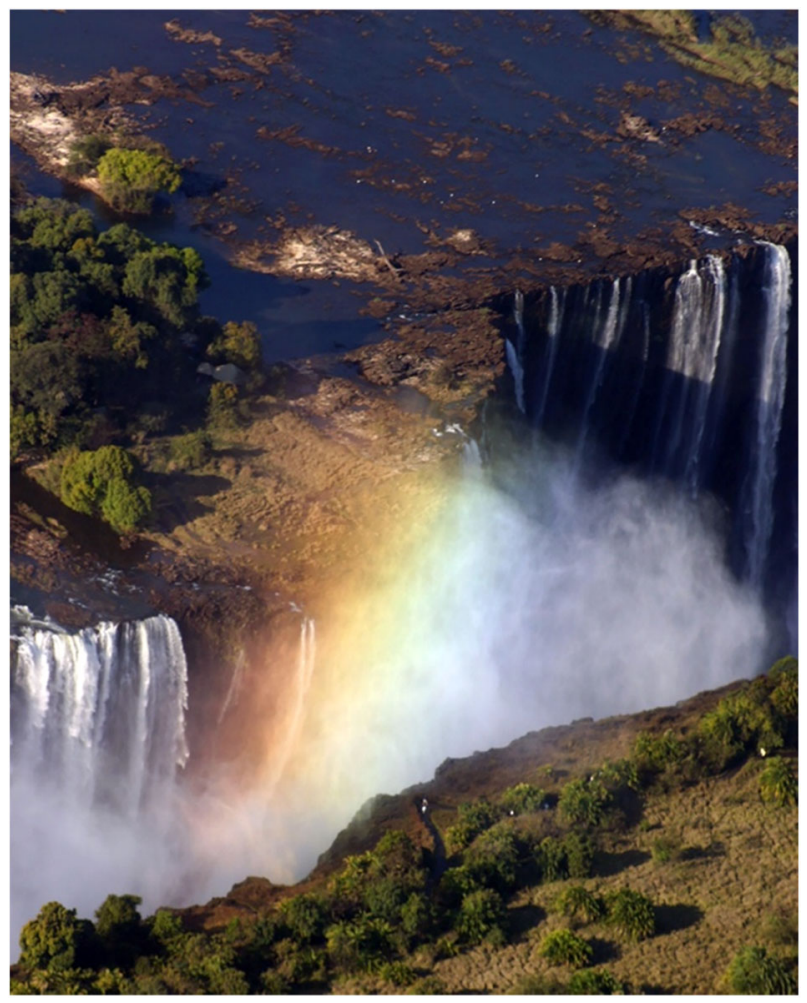

Fig. 5 Spectral colors appear not only in the sky but wherever water droplets can suspend in the air, Victoria Falls, Zambia, helicopter aerial view. Photo and (C) MICHALOUS, 2010

these photos we will examine some attempts to experiment with sunlight over optical prisms in order to observe rainbows (Figs. 6, 7) and to create rainbow holograms on the body of silica aerogel/sky.

The rainbow is a terrestrial natural phenomenon that possibly has generated the most wonder, awe and mystery in human history. With a phantom-like translucent silhouette and the element of unexpected surprise of this fleeting spectacle, we have made rainbows the protagonists of a vast variety of myths, urban legends and tales. Rainbows seem to have spiked the creativity and imagination of humans and many art pieces were created as an ode to this unique spectacle. Hence rainbows are perhaps the natural sky-phenomenon that influenced the human thought the most [21].

Every rainbow is a unique, a spectacular phenomenon in the sky that does not happen as often as other more "common" natural phenomena, thus often generates awe and takes your breath away, leaving the viewers pensive. Infused by light and moist, constituted a harmonious union that produces a symbol of hypernatural beauty, hope and enlightenment.

The most familiar type of rainbow, is produced when the incident sunlight strikes raindrops in front of a viewer at a precise angle of $42^{\circ}$. The appearance of a rainbow depends 


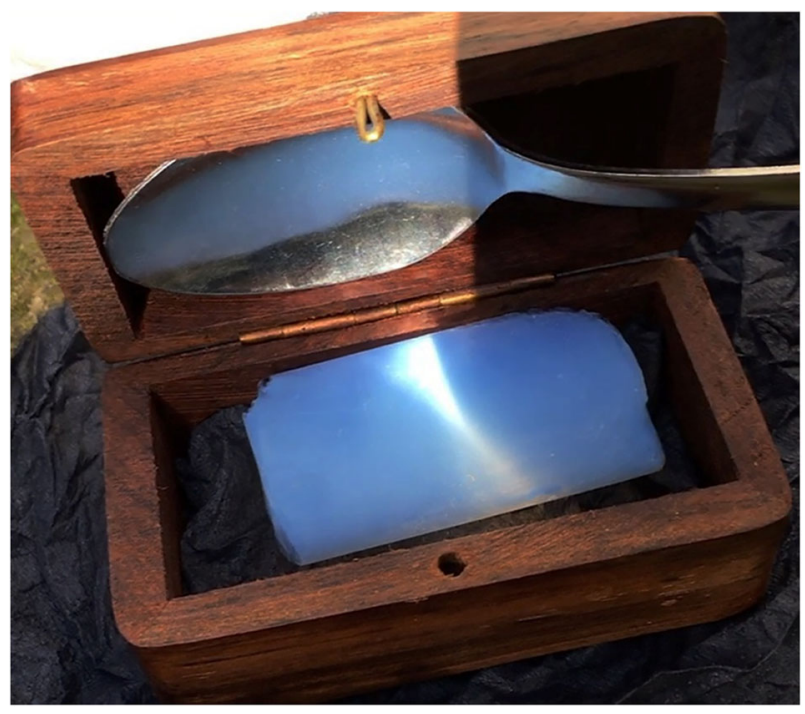

Fig. 6 Experimenting with sunlight reflected on the concave mirror of a teaspoon. The sunlight ray concentration diagram we learned in physics is well visualized and documented as a three-dimensional sunlight hourglass. The half of the three-dimensional " $\mathrm{X}$ " has a bright white color and the other half has a golden hue because of the Rayleigh scattering phenomenon. A movie for this figure is also available in the Supplementary Material (Mov. S3). Photo and (C) MICHALOUS, 2020

on where you are standing and where the sun is shining. Light entering a water droplet is refracted. It is then reflected by the back of the droplet. As this reflected light leaves the droplet, it is refracted again, at multiple angles.

The rainbow is a visual illusion, it does not exist at a specific point in the sky. After rain during daytime, if we are in the right place and look over the horizon, we will see the rainbow. Observing this glowing arch, one can theorize that it resembles a bridge between heaven and earth. Mentally following this path, we are enabled to investigate the deepest parts of ourselves in a quest of finding peace and clarity, freeing ourselves from our problems and experiencing feelings of hope and optimism. Therefore, Rainbow often symbolizes self-empowerment and confidence.

In Greco-Roman mythologies, the arch of color was a path drawn by the young, alluring and changeable. Ultimately Iris used the rainbow arch as a bridge to carry the messages of Zeus and she became the personification of the colorful sky phenomenon.

After Iris was evicted from heaven by Descartes, she migrated on in a very humble and private location within the cosmos. Each person has a ring of color surrounding their eye's pupils which serves as a threshold, a door of their inner deep and wondrous. Psyche and the outer world of a more modest reality. That colorful ring and window to a person's soul still holds the name of the beautiful goddess "Iris" [21, 22]. This means that everyone carries a piece of rainbow with them. The unique rainbow of everyone, that

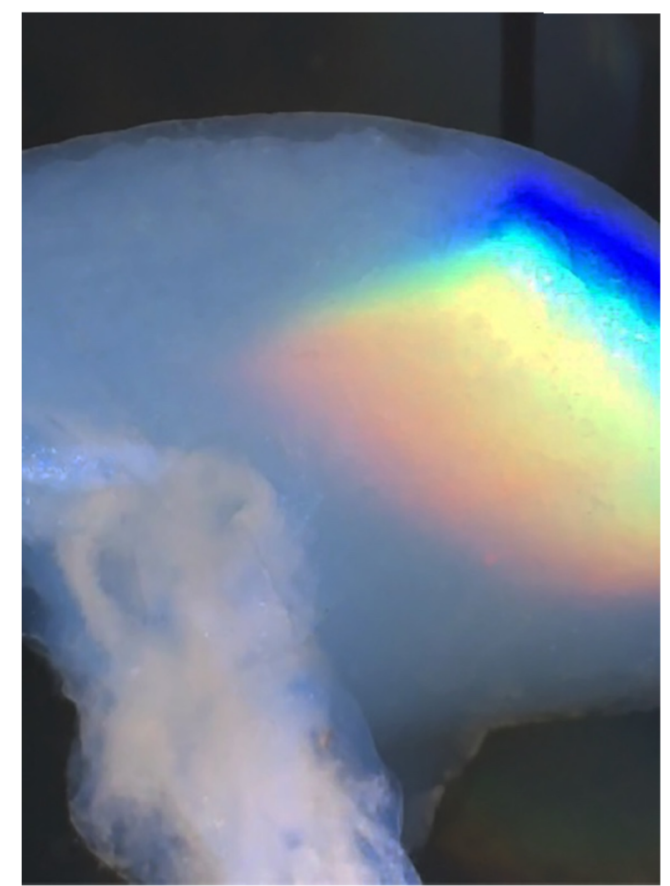

Fig. 7 Experimenting with direct sunlight passing through a triangular optical prism and directed into a silica aerogel hemisphere of a diameter of $150 \mathrm{~mm}$. The sunlight is bent because of the prism and the majestic spectral colors appear into silica aerogel/sky. A movie for this figure is also available in the Supplementary Material (Mov. S4). Photo and (c) MICHALOUS, 2020

you look for when the sky around you is dim, to travel you to its vastness and to offer you the magic of its colors.

\section{Rainbow hologram on silica aerogels}

A preliminary engineering work has been carried out at Nanotypos [23] who have demonstrated high security hologram devices having sub-100 $\mathrm{nm}$ resolution proficient to be viewed in both reflection and transmission mode. The produced holograms represent real colors through nano structuring (surface patterning), offering enhanced security and high-quality decorative features. A combination of semiconductor processes in information communication technology, such as electron beam lithography and reactive ion etching techniques, have been used to create the master mold/stamp which contained the diffractive (rainbow hologram) structures.

The rainbow hologram surfaces were fabricated by an alternative nanomanufacturing technique, namely, nanoimprint lithography (NIL, Fig. 8) [24]. NIL is an emerging lithography technique capable of patterning sub-10 nm features at high throughput rates. Due to its low cost of ownership and feasibility NIL has attracted attention mainly from the semiconductor industry. This parallel process relies on the mechanical deformation of a thin polymer 

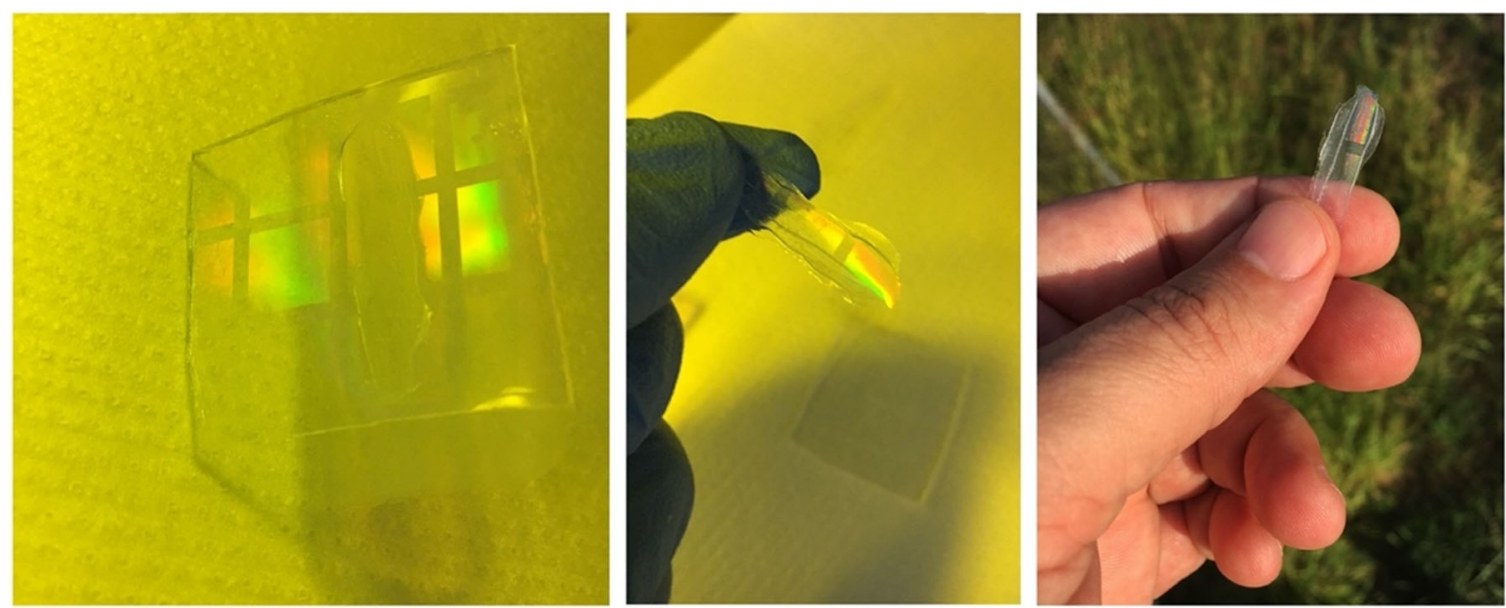

Fig. 8 The initial attempt of producing rainbow hologram colors on the external surface of silica aerogel were performed by ultraviolet light assisted nanoimprint lithography (UV-NIL). A drop of an organicinorganic hybrid resist provided by microresist technology $\mathrm{GmbH}$ (named OrmoComp) was drop casted onto a thin PDMS mold which incorporated nano scale grating structures. A piece of $2 \times 2 \times 1 \mathrm{~cm}$ silica aerogel was carefully deposited on the Ormocomp-PDMS assembly (left). The complete assemble was exposed to UV light for $5 \mathrm{~s}$, while carefully peeling-off the PDMS allowed the nanostructured Ormocomp material to separate (middle). Here we see three images of the holographic effects of the aerogel-Ormocomp assemble (right). Photos: NK
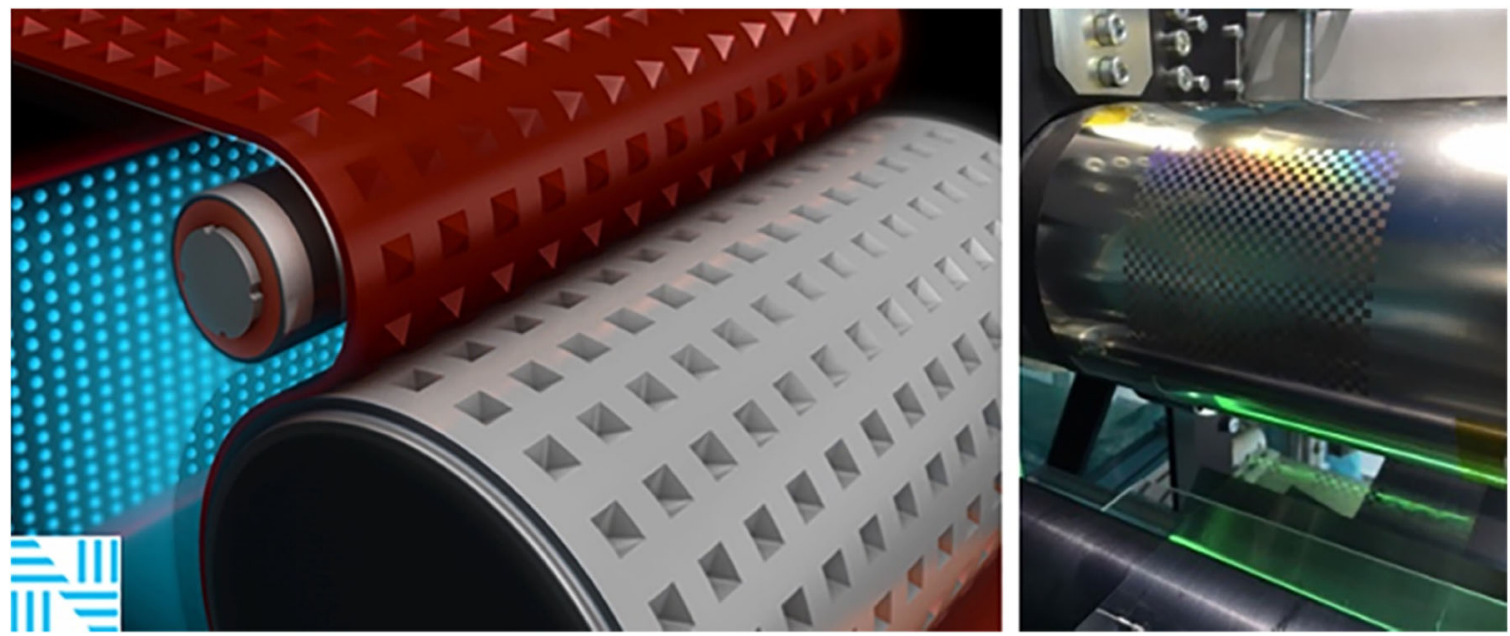

Fig. 9 For our R2R UVNIL imprinting, we used reverse gravure coating technique to ensure thin $(<500 \mathrm{~nm})$ coating of our PET substrate. The PDMS flexible stamp was attached to a cylindrical backbone roll while UV light $(365 \mathrm{~nm})$ was applied through the back side

layer. Due to its nature, it is a one-by-one process meaning that any structural patterns on the stamp will be transferred to the imprinted thin polymer film. A modification of the NIL process which uses a cylindrical stamp has been developed in the last year. This new manufacturing process namely, the roll-to-roll nanoimprint lithography (R2RNIL) [25], has the potential to enable low cost, high-rate manufacturing of engineered functional surfaces (Fig. 9).

Our experimental set up consisted of a 200-mm wide web roll-to-roll nanoimprinting machine. Our imprinting tool consisted of an unwinding unit, a reverse gravure coating unit, an infrared (IR) drying unit, the embossing unit and a rewinding unit. All units are electronically of the substrate (left). Reverse gravure coating was utilized to coat a PET film with Ormocomp resist which was thinned down to achieve the desired thickness (right)

controlled and allow us to control the speed and tension of our web from $0.5 \mathrm{~m} / \mathrm{min}$ up to $5 \mathrm{~m} / \mathrm{min}$. Imprinting of our coated film was performed by ultraviolet (UV) light assisted roll-to-roll nanoimprint lithography (R2R UVNIL) using a flexible poly(dimethylsiloxane) (PDMS, Sylgard 184 kit) stamp. The PDMS mold was fabricated by casting the PDMS prepolymer against the relief structure of the silicon master mold. We used the PDMS precursor with a mixing ratio of 10:1 (precursor: curing agent) and let it cure for $18 \mathrm{~h}$ at $60{ }^{\circ} \mathrm{C}$. We optimized the thickness of the PDMS molds to be $2 \mathrm{~mm}$ in order to avoid pattern deformation.

For our R2R UVNIL, we used reverse gravure coating technique to ensure thin $(<500 \mathrm{~nm})$ coating on our PET 

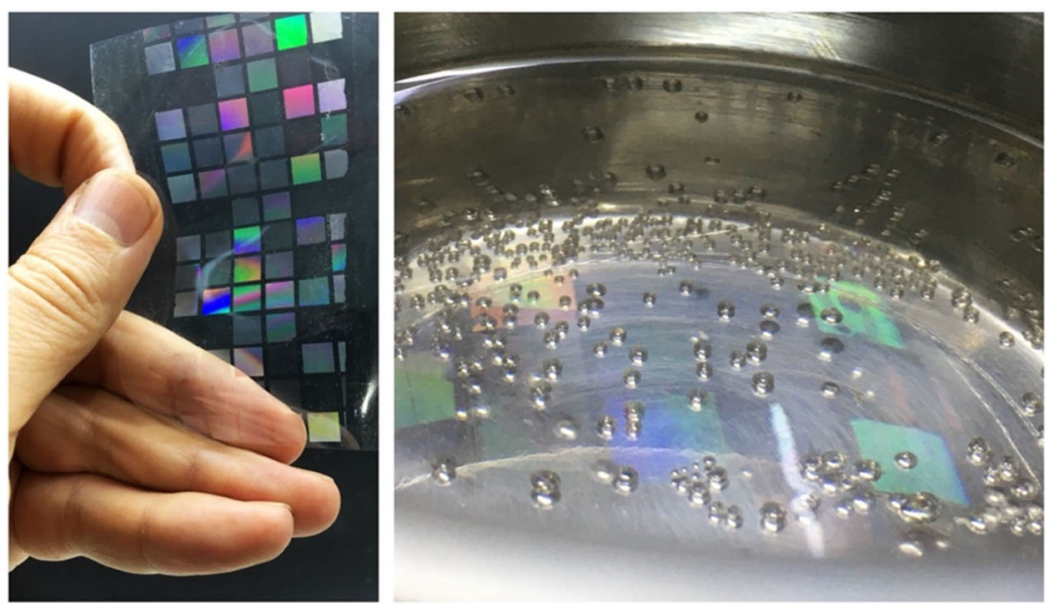

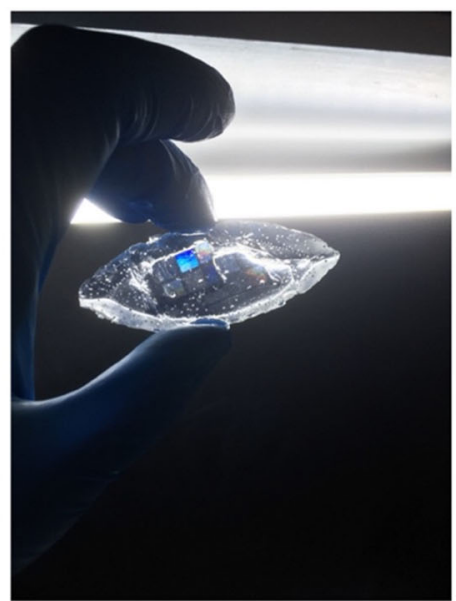

well transferred onto the alcogel. A movie for this figure is also available in the Supplementary Material (Mov. S5). Photos and (C) MICHALOUS, 2020

poured the sol into the mold so the PET piece was covered well with the sol. Once gelation was occurred (here very rapidly because of a high ambient temperature in the lab, causing bubbles), we demolded the wet gels into a methanol bath. The PET was peeled off before supercritical drying. The alcogel thus obtained was processed with high-temperature supercritical drying for $20 \mathrm{~h}$. The results of the rainbow are visible under sunlight. Nevertheless, the square motif was not visible, possibly because PET was not well stuck to the bottom of the mold and started to bend with heat produced during the gelation. A series of materials we obtained by this procedure is shown in Fig. 10. It should be noted that the hologram motif was maintained during the high-temperature supercritical drying in methanol (Fig. 11).

The R2R UVNIL was performed at ambient temperature while protective covers prohibited our UV curable resist to be exposed to ambient light. The uniformity of the resist coated film and imprinted structure is governed by the control of the web tension.

In the 14th century Theodoric discovered that rainbows are actually resulted both from the refraction and reflection of light through individual raindrops. In the late 17th century Newton, using a prism, discovered that white light (ex. sunlight) contains a phantom-like spectrum of an array of colors that can be blended and faded in white. Hence, relevant to the lyrical representation of raindrops as diamonds in the sky, one can speculate as a more poetic parallelism of the Newtonian physics theories. Alas, the human marvel towards rainbows, was not bereft when a more solid explanation was given based on hard science. On the contrary, rainbows imagery still represents in current art and media an otherworldly element that can carry messages and symbols woven in human archetypal collective experience. bottom of the mold (a metallic boiling mold), and then 

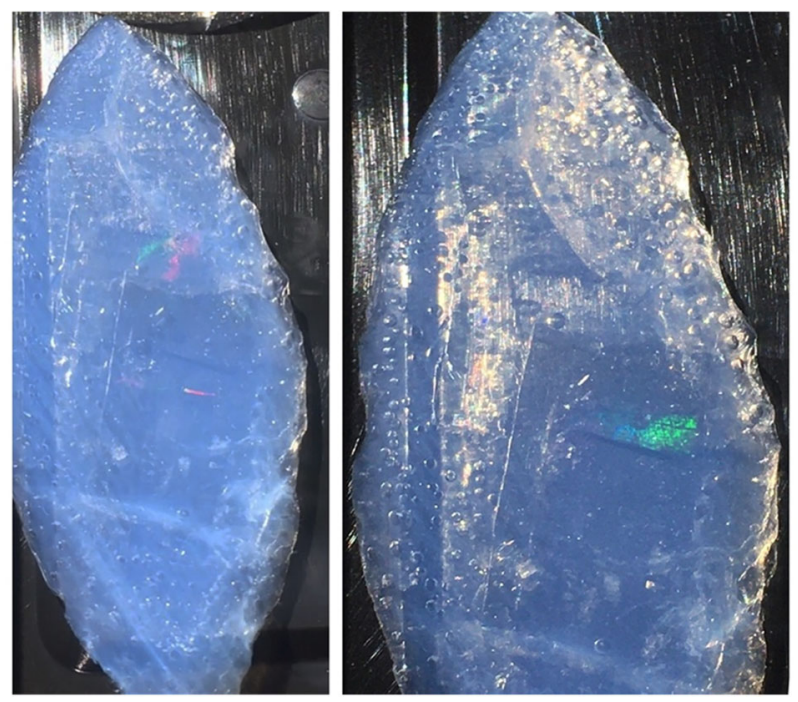

Fig. 11 The rainbow hologram motif is remaining visible after the high-temperature supercritical drying of the silica alcogel; except the squared motif is now disoriented. A movie for this figure is also available in the Supplementary Material (Mov. S6). Photos and (C) MICHALOUS, 2020

\section{Homage to Benton}

Holograms are mediums that upon illumination with a first wave front, generate a second wave front that constitutes to an optical reconstruction in a three-dimensional space. After the invention of the laser, Leith and Uptnieks invented offaxis holography, while Denisyuk invented volume reflection holography. In 1969 Benton (Professor Stephen Benton was the Director of the MIT's Center for Advanced Visual Studies when IM started his research to apply silica aerogel in Visual Arts. Into a support letter of the 14th Nov. 2002 for the artist, the immemorable Benton mentioned: “...I should add that his first aerogel sculpture, -Icare, I care, was successfully presented during the Sky Art Conference 2002, in Greece, (Delphi and Ikaria, 15-20 Oct.) where I was present as the Director of the CAVS. It is worth noting that the 15th of October 2002 was the worldwide premiere of a silica aerogel sculpture!".) invented rainbow holography, where white light reconstruction of off-axis holograms became possible at the expense of vertical parallax. The subsequent development of micro embossing technique allowed mass production (replication) of the rainbow holograms. The first commercial application of holograms was realized in 1980 where rainbow holograms were embossed as security features on valuable documents and products by the United States Banknote Company. All security features are characterized by an iridescent display of colors with angle of observation, and such security features are referred to optically variable devices, or OVDs. The diffractive type security feature is frequently referred to as diffractive optically variable image device (DOVID), while interference type security features are continually known as interference security image structures. Although the most commonly used method of fabricating DOVID structures is laser interference lithography techniques these methods have been replaced by more complicated and advanced lithographic techniques (electron beam lithography) resulting in higher security devices.

Even in current times, rainbow is still a protagonist in popular culture. In cinematography the rainbow imagery often is used by the famous film director Stanley Kubrick to symbolize a cosmogenous change or a so-called limbo and in-between place, an unsettling bridge between normal everyday life and a more adventures, sinister even forces that might drive the innate world of the protagonists [27].

Currently, due to the outbreak of the Covid-19 pandemic globally, various measures were introduced since February 2020, including social distancing. The confinement measures have put a strain on all factors of human life and experience, socially, professionally and in many cases physically. Amid the coronavirus outbreak, as millions of people are restricted at home, various media reports have been talking about rainbow symbols making their appearance outside windows across the world. Often is a rainbow drawing on a piece of paper or cloth and it is believed to be used because of its properties as a pan-anthropic symbol of hope and it is used these bleak times to create and enhance a sense of community and connectedness [28].

\section{Conclusion in nanoWOR(L)DS}

We have demonstrated that silica aerogel sculptures could be fabricated by a combination of alternative nanopatterning techniques and standard aerogel preparation process and used as high-end art products. The diffractive color effect can be tuned by the dimensions of the nanostructures. The combination of emerging lithography techniques with nanomaterials presents a novel artificial material which may find potential applications in the design and fashion industry. Further development of our prototype sculptures manufacturing technology is under progress, and works on upscaling, controlling material properties and exploring new visual effects are under investigation.

We know that a construction engineer is constantly caught between two contradictory desires: "To use as little material as possible, to reduce the cost price and avoid collapse which costs even more than a good construction [29]".

The conceptual artist Marcel Duchamp showed us that all the arts, without excluding the visual arts, are born and end in an invisible zone. To the lucidity of instinct, he opposed the instinct of lucidity: the invisible is neither obscure nor mysterious; it is transparent [30]. 
This paper, shattered as our heaven [31], not only provides 'information' as data, but also seeks to provoke readers to actively participate in the creative transformation of scientific information into knowledge through the lens of visual arts.

The rationale for artistic metaphors and allegories addressed to a scientific audience, affirms that the 'interdisciplinary', 'in-between' dimensions of human knowledge and experience, (like a rainbow) can best be explored through the intersecting methodologies and mythologies of artists and scientists [32].

The mathematician, Henri Poincaré, wrote on a 'representative space' which cannot be measured, but only felt: this non-Euclidean space exists in-between the dimensions we can recognize.

The imaginability of complex human aspirations, reflects an impulse towards a kind of 'free-dimensionality' as the basis of creative, transformative thinking [33].

Acknowledgements The authors would wish to thank the company Nanotypos (http://www.nanotypos.com/) for providing stamps and their pilot roll to roll nanoimprint lithography equipment for testing purposes. The ever-memorable Professor Steven Benton who was the Director of the MIT's Center for Advanced Visual Studies when the artist was a Research Affiliate at MIT. The company Aerogel Technologies (http://www.aerogeltechnologies.com/) and NCSR Demokritos for supporting our Science in Art initiatives.

\section{Compliance with ethical standards}

Conflict of interest The authors declare no competing interests.

Publisher's note Springer Nature remains neutral with regard to jurisdictional claims in published maps and institutional affiliations.

\section{References}

1. Octavio P (1993) L'arc et la lyre, translated from Spanish by Roger Munier. Gallimard, collection "nrf / Essais", Paris, p. 98.

2. Shimizu T, Kanamori K, Nakanishi K (2017) Silicone-based organic-inorganic hybrid aerogels and xerogels. Chem Eur J 23:5176-5187

3. Hunt A (1998) Light scattering for aerogel characterization. J Non-Cryst Solids 225:303-306

4. Emmerling A, Petricevic R, Beck A, Wang P, Scheller H, Fricke J (1995) Relationship between optical transparency and nanostructural features of silica aerogels. J Non-Cryst Solids 185:240-248

5. Zhao L, Strobach E, Bhatia B, Yang S, Leroy A, Zhang L, Wang EN (2019) Theoretical and experimental investigation of haze in transparent aerogels. Opt Express 27:A39-A50

6. Sumiyoshi T, Adachi I, Enomoto R, Iijima T, Suda R, Yokoyama M, Yokogawa H (1998) Silica aerogels in high energy physics. J Non-Cryst Solids 225:369-374

7. For Marcel Proust's "Me in parentheses", see his books: Le Temps Recovered, Paris, Gallimard, Pléiade, 1954, volume III, p. 879 sq. and 'Against Sainte-Beuve", Paris, Gallimard, Pléiade, 1971, p. 303

8. Marcel D (1976) Duchamp du Signe, writings collected and presented by Michel Sanouillet. Flammarion, Paris, p. 7.
9. Gaston B (1994) The poetics of space, op. cit., chap. VII. "The miniature", pp. 140-167, p. 151. La poétique de l'espace. P.U.F, (Quadrige), Paris.

10. Michaloudis I, Dann B (2017) Aer()sculpture: Inventing skies and microclouds into diaphanous sculptures made of the space technology nanomaterial silica aerogel. J Sol-Gel Sci Technol 84:535-542

11. Wassily K (1989) On the Spiritual in Art and in Painting in particular, ed. established and presented by Philippe Sers, (translated from German by Nicole Debrand and from Russian by Bernadette du Crest). Denoël, Collection "Folio/Essais", Paris, p. 140.

12. Tillotson TM, Hrubesh LW (1992) Transparent ultralow-density silica aerogels prepared by a two-step sol-gel process. J Non-Cryst Solids 145:44-50

13. Michaloudis I, van Roden M (2017) Spirited Skies project: Silica aerogel in art and design applications. MRS Adv 2:3491-3497

14. Michaloudis I (1999) Androgynous' Garment, Doctoral dissertation, Atelier National de Reproduction des Thèses, France, p.18, http://www.theses.fr/1998PA010606. Accessed 12 Jul 2021

15. Mircea E (1963) Aspects du myth. Gallimard, Collection "Folio/ Essais", Paris, 1988, pp. 115-116.

16. Henri Focillon, The Life of Forms in Art, (transl. George Kubler), Zone Books, 1989, p. 57.

17. Wassily Kandinsky, On the Spiritual in Art and in Painting in particular, ed. established and presented by Philippe Sers, (translated from German by Nicole Debrand and from Russian by Bernadette du Crest), Paris, Denoël, Collection "Folio / Essais", 1989, p. 107.

18. Michalou(di)s I, Carroll MK, Kupiec S, Cook K, Anderson AM (2018) Facile method for surface etching of silica aerogel monoliths. J Sol-Gel Sci Technol 87:22-26.

19. Michaloudis I (2004) Aer()sculpture: the enigmatic beauty of aerogel's non-entity in a pilot art \& science project. J Non-Cryst Solids 350:61-66

20. Papachristopoulou K, Vainos NA (2020) Systolic nanofabrication of super-resolved photonics and biomimetics. Nanomater 10:2418.

21. Utke AR (1996) The rainbow: A universal timeless 'pointer' toward ultimate reality and meaning. Ultimate Real Mean 19:22-39

22. Faena A (2021) Rainbows: A journey through their history in art. https://www.faena.com/aleph/rainbows-a-journey-through-theirhistory-in-art. Accessed 12 Jul 2021

23. http://www.nanotypos.com/. Accessed 12 Jul 2021

24. Chou SY, Krauss PR, Renstrom PJ (1995) Imprint of sub-25 nm vias and trenches in polymers. Appl Phys Lett 67:3114-3116

25. Mäkelä T, Jussila S, Vilkman M, Kosonen H, Korhonen R (2003) Roll-to-roll method for producing polyaniline patterns on paper. Synth Met 135-136:41-42

26. Bhuiya MMH, Anderson AM, Carroll MK, Bruno BA, Ventrella JL, Silberman B, Keramati B (2016) Preparation of monolithic silica aerogel for fenestration applications: Scaling up, reducing cycle time, and improving performance. Ind Eng Chem Res 55:6971-6981

27. Puhr T (2017) Four frames: Rainbow imagery and the otherworldly atmosphere of Eyes Wide Shut. http://thebigpicturemaga zine.com/four-frames-how-rainbow-imagery-creates-an-otherw orldly-atmosphere-in-eyes-wide-shut/. Accessed 12 Jul 2021

28. Vince G (2020) Rainbows as signs of thank you, hope and solidarity. https://www.bbc.com/culture/article/20200409-rainbows-a s-signs-of-thank-you-hope-and-solidarity. Accessed 12 Jul 2021

29. André D (1966) La résistance des matériaux (Resistence of Materials, 1953, 4è éd. P.U.F, (Que sais-je?, No 599), Paris, p. 8

30. Octavio P, Marcel Duchamp: l'apparence mise à nu..., (1966), transl.from Spanish Monique Fong. Gallimard, 1977, (NRF/ Essais), Paris, p. 15 
31. Paton D, Michaloudis I, Pavavalung E, Clark K, Buergelt P, Jang L, Kuo G (2017) Art and disaster resilience: Perspectives from the visual and performing arts. In: Paton D, Johnston DM (eds) Disaster resilience: An integrated approach, 2nd edn. Charles C Thomas Publisher, Springfield, IL, 212-6235
32. Michaloudis I, Seats M (2014) Etherospermia: Conceptual art, science and allegory in the sky-seeding project. Acta Astronaut 104:61-70

33. Michaloudis I (2011) Aer()sculpture: A free-dimensional space art. In: Aegerter MA, Leventis N, Koebel MM (eds) Aerogels Handbook, Springer, New York, 791-6810 